Article

\title{
What Works in School-Based Programs for Child Abuse Prevention? The Perspectives of Young Child Abuse Survivors
}

\author{
Jeanne Gubbels $^{1, *(\mathbb{D})}$, Mark Assink ${ }^{1}(\mathbb{D})$, Peter Prinzie ${ }^{2}(\mathbb{D})$ and Claudia E. van der Put $^{1}$ \\ 1 Research Institute of Child Development and Education, University of Amsterdam, Nieuwe Achtergracht 127, \\ 1018 WS Amsterdam, The Netherlands; M.Assink@uva.nl (M.A.); C.E.vanderPut@uva.nl (C.E.v.d.P.) \\ 2 Erasmus School of Social and Behavioral Sciences, Department of Psychology, Education \& Child Studies, \\ Erasmus University Rotterdam, Burgemeester Oudlaan 50, 3062 PA Rotterdam, The Netherlands; \\ Prinzie@essb.eur.nl \\ * Correspondence: J.Gubbels@uva.nl
}

Citation: Gubbels, Jeanne, Mark Assink, Peter Prinzie, and Claudia E. van der Put. 2021. What Works in School-Based Programs for Child Abuse Prevention? The Perspectives of Young Child Abuse Survivors. Social Sciences 10: 404. https:// doi.org/10.3390/socsci10100404

Academic Editor: Nigel Parton

Received: 7 September 2021

Accepted: 14 October 2021

Published: 19 October 2021

Publisher's Note: MDPI stays neutral with regard to jurisdictional claims in published maps and institutional affiliations.

Copyright: (c) 2021 by the authors. Licensee MDPI, Basel, Switzerland. This article is an open access article distributed under the terms and conditions of the Creative Commons Attribution (CC BY) license (https:// creativecommons.org/licenses/by/ $4.0 /)$.

\begin{abstract}
Previous research has shown that youth consider school-based child abuse prevention programs as one of the most important strategies for preventing child abuse and neglect. This study asked young child abuse survivors how school-based child abuse prevention programs should be shaped and what program components they perceive as essential. Semi-structured interviews were conducted with 13 Dutch young adults that were a victim of child abuse or neglect. A literature review that resulted in 12 potential program components was used to guide the interviews. All young adults agreed that school-based child abuse prevention programs are important and have positive effects on children's awareness of child abuse. Teaching children that they are never to blame for child abuse occurrences was considered one of the most important components of school-based programs, next to teaching children how to escape from threatening situations and to find help, increasing children's social-emotional skills, promoting child abuse related knowledge, recognizing risky situations, and increasing children's self-esteem. Further, the participants found it important to provide children with aftercare when a school program has ended. Overall, young child abuse survivors have a strong view on what should be addressed in school-based child abuse prevention programs to effectively prevent child abuse.
\end{abstract}

Keywords: school-based programs; child abuse; prevention; child abuse survivors; young adults

\section{Introduction}

Child abuse is a major public health problem with serious and enduring consequences for victims (e.g., Cicchetti 2016; Stoltenborgh et al. 2015). Therefore, effective prevention of child abuse is essential. Here, schools play an important role, as most children attend school daily, providing opportunities for teachers and other school staff to detect child abuse risk factors (Gilbert et al. 2009; Nickerson et al. 2019). The school setting is ideal for program delivery as it provides access to the general population through which many children can be reached in a relatively cost-effective way (Asawa et al. 2008; Dhooper and Schneider 1995). School-based programs are therefore promising for primary child abuse prevention. Review studies showed positive effects of school-based prevention programs on abuse related knowledge, self-protection skills, and abuse disclosure (see, for example, Davis and Gidycz 2000; Topping and Barron 2009; Walsh et al. 2018). In the Netherlands, there is often no attention paid to child abuse prevention at schools, potentially due to the absence of national regulations or policy requiring schools to address child safety or abuse prevention. However, various Dutch school-based programs are available and child abuse education is considered an important prevention method by teachers and youth (Gubbels et al. 2021a; Pieper and De Haan 2017). This qualitative study aimed to examine the perspectives of young child abuse survivors on school-based child abuse prevention 
programs, how these programs should be shaped, and what components are important in school-based prevention programs.

\subsection{School-Based Child Abuse Prevention Programs}

School-based child abuse prevention programs often focus on increasing children's knowledge about child abuse and/or on teaching children protective skills, so that the risk of child abuse is reduced (Blakey and Thigpen 2015). This knowledge and skills make children more aware of abusive or unsafe situations and encourage children to disclose child abuse (Ko and Cosden 2001). Topics often covered in school-based programs are recognizing and avoiding abusive situations, identifying and disclosing abuse to trusted adults, having the skills to say 'no' and/or escape abusive situations, and learning that child abuse is never a child's fault (MacIntyre and Carr 2000; Nickerson et al. 2019).

Several meta-analytic reviews have been conducted to investigate the effectiveness of child abuse education programs in schools (Davis and Gidycz 2000; Gubbels et al. 2021b; Rispens et al. 1997; Walsh et al. 2018). These studies showed that children participating in school-based programs had significantly more knowledge about (the prevention of) child abuse, showed better self-protection skills, and disclosed potential abuse more often than children who did not participate in school-based programs. Furthermore, a retrospective study in which questionnaires were administered to 800 female university students showed that participation in a school-based child abuse prevention program was associated with fewer incidents of sexual abuse victimization (Gibson and Leitenberg 2000).

Recently, Gubbels et al. (2021b) conducted a meta-analysis on the overall effect of school-based child abuse prevention programs and identified what specific program components are associated with overall program effectiveness. They found a significant overall effect of school-based programs on both children's child abuse-related knowledge $(d=0.572)$ and self-protection skills $(d=0.528)$. Further, they found larger program effects on children's child abuse knowledge for programs addressing the social-emotional skills of children, such as improving empathy with peers, and learning to express emotions or learning social problem-solving skills. Larger effects were also found for programs teaching children to avoid self-blame and to realize that abuse is never a child's fault. These results imply that program effectiveness can be improved by implementing specific components.

\subsection{School-Based Programs in the Netherlands}

In the Netherlands, several Dutch school-based programs for child abuse prevention are available, though child abuse education is often not part of the standard curriculum of primary or secondary schools (Gubbels et al. 2021a). Although Dutch schools are obligated to ensure physical and social safety for all students and teachers (Ministry of Education, Culture, and Science 2015), there are no national regulations requiring schools to educate children about child safety or abuse and no policy requirements for school-based child abuse prevention programs. In a nationwide panel study, Dutch adolescents indicated that they wanted to be informed about the concept of child abuse and about how to act when they detect abuse with peers through lessons at school (NJR 2013). However, there was hardly any attention paid to child abuse education in their schools. The adolescents indicated that proper education is needed to teach children to recognize abuse and learn about how to handle it, for instance, by talking about the abuse with a trusted adult or by calling the child abuse hotline (NJR 2013). In a more recent study, adolescents with a history of child abuse also suggested that children should be informed at school about their rights, family violence, and potential sources of support (Augeo 2018). Finally, the results from a study examining the views and opinions of adolescents and parents on effective prevention of child abuse indicated that education about child abuse was viewed as one of the most important ways to prevent child abuse (Pieper and De Haan 2017). Both adolescents and parents agreed that this education should start in primary school and should be tailored to the children's age. Together, these findings show that, although there is a great need for children and adolescents to be informed about child abuse through education programs at 
school, there is currently hardly any attention paid to this in Dutch primary and secondary education.

\subsection{The Current Study}

Although adolescents and their parents consider school-based programs as very important for the prevention of child abuse (Pieper and De Haan 2017), it was not yet known how these programs should be shaped (e.g., content, duration, program leader, etc.) and which specific program components are important. Therefore, we aimed to examine the perspectives of young child abuse survivors on school-based child abuse prevention programs. We asked them to which extent these programs may have helped them in their childhood, and how these programs should be shaped. We also asked them what components they find important in school-based prevention programs. For the latter we made use of a list of 12 program components that were described in the review of Gubbels et al. (2021b), including (1) promoting child abuse related knowledge; (2) learning about safe and unsafe secrets; (3) learning about personal rights; (4) teaching children to avoid self-blame; (5) learning about body and boundaries; (6) identifying a trusted person; (7) increasing social-emotional skills; (8) recognizing risky situations; (9); increasing assertiveness skills; (10) learning to go away or find help; (11) increasing children's self-esteem; (12) to disclose abuse.

\section{Methods}

This study used a qualitative interview design and examined a sample of abused young adults. The design of this study, as well as the study findings, are reported according to the Consolidated criteria for reporting qualitative research (COREQ) that were developed to facilitate explicit and comprehensive reporting of qualitative studies (Tong et al. 2007).

\subsection{Participants}

Semi-structured interviews were conducted with 13 young adults aged between 19 and 36 years $(M=24.46$ years; $S D=5.75)$ and that have a history of childhood abuse or neglect victimization. The participants were recruited by approaching two Dutch organizations that give a voice to child abuse survivors in education, policy, and clinical practice ('Augeo Youth Taskforce' and 'Team-Kim').

\subsection{Procedure}

First, the above-described organizations were contacted and informed about the aims of the current study. Next, the criteria for recruitment of participants and the procedure for the interviews was discussed with the directors of both organizations. Then, a study recruitment text was shared with all juveniles and young adults affiliated with the two organizations. The young adults who volunteered to participate received detailed information on research participation and signed an online informed consent form. By signing this form, the participants confirmed that they had read and understood the information and gave consent for participation and the use of the obtained data for research. In the consent form, it was made clear to the participants that they had the right to withdraw their consent or to stop their participation at any time, without any reason.

Each interview was scheduled with two participants at the same time. These 'joint interviews' have several advantages, such as establishing opportunities for participants to complement each other, providing the interviewer the possibility of exploring consensus and conflict between the participants, and establishing a more confidential atmosphere (Highet 2003; Houssart and Evens 2011). Due to scheduling issues, three participants had to be interviewed individually.

A total of eight interviews were conducted by the first author, a female PhD candidate, who had experience in conducting semi-structured interviews (see, for example, Gubbels et al. 2021c). The interviews took place during the COVID-19 pandemic and, therefore, all interviews were held via a videoconferencing platform. Research shows that 
videoconferencing is quite suitable for collecting qualitative data because of its relative ease of use, cost-effectiveness, and security options (Archibald et al. 2019). Each interview started with a brief introduction of the study, after which participants were asked for permission to record the interview and were informed that all personal data were anonymized for this study. Participants were also given the opportunity to ask questions before the interview began. The interviews lasted about $45 \mathrm{~min}$. At the end of each interview, the participants were thanked for their participation and they received a voucher of $€ 50$ as compensation for their cooperation. All data collected during this study were stored at a secure online location, with access only provided for researchers. The Ethics Committee of the Faculty of Social and Behavioral Sciences of the University of Amsterdam approved this study (project number 2021-CDE-13000).

\subsection{Instruments}

An interview guide was used in each semi-structured interview (available from the corresponding author on request). The interview questions were approved by the recruiting organizations to make sure that questions were in line with the participants' context. Examples of interview questions are: "What do you think about child abuse education in school?" and "Could child abuse education have improved your situation?" We asked one participant in the first joint interview to give feedback on the interview questions, after which some small adjustments were made to the interview questions for clarification purposes.

As the literature indicates that school-based child abuse prevention programs have positive effects on children's child abuse-related knowledge and self-protection skills (Davis and Gidycz 2000; Gubbels et al. 2021b; Rispens et al. 1997; Walsh et al. 2018), questions regarding these effects were included in the interview. Further, the participants were shown an overview of 12 specific program components extracted from the work of Gubbels et al. (2021b) on which the content of a school-based child abuse prevention program could be based. For clarification purposes, we divided the components into two sets of six components and asked the participants which components they viewed as most important. The first set of components included: (1) promoting knowledge on child abuse or prevention concepts or definitions; (2) learning about safe and unsafe secrets (i.e., secrets that are okay or not okay to keep); (3) increasing awareness of children's personal rights (e.g., rights to be safe, rights over their own body); (4) teaching children to avoid self-blame (that abuse is never a child's fault); (5) learning about own body and boundaries (e.g., learning about private parts, safe or unsafe touch); (6) identifying a trusted person (e.g., identify people in family, building a community support system). The second set of components comprised: (7) increasing social-emotional skills (e.g., empathy with peers, social problem-solving skills); (8) recognizing and avoiding risky situations (e.g., recognize potentially abusive situations or potential abusers); (9) increasing assertiveness skills (e.g., saying 'no', standing up for oneself); (10) learning to go away from a potential abusive situation or to find help; (11) increasing a child's self-esteem; (12) learning skills to disclose abuse (e.g., encouraging children to report abuse to a trusted adult, developing the vocabulary needed to report).

\subsection{Data-Analysis}

Audio recordings were made during the interviews, which were transcribed and coded using the software ATLAS.ti, version 9. Coding was done according to the method described by Boeije (2009), comprising the steps of open coding, axial coding, and selective coding. First, each passage was studied after which it was labeled with a code (open coding). Next, all passages of each interview were compared to determine overlapping themes (axial coding). Finally, connections between codes within these themes were determined (selective coding), which was done by creating a network for each theme showing contradictions and resemblances between codes. All interviews were coded by 
two coders, the first author of this study and a trained research assistant. The first author resolved any inconsistency in coding after which the final coding was reached.

\section{Results}

The results are presented following nine key themes generated in the data analysis: (1) general view on school-based child abuse prevention programs, (2) goals and positive effects of school-based programs, (3) own experiences with school-based programs, (4) effects of school-based programs on knowledge, (5) effects of school-based programs on self-protection skills, (6) potential negative effects of school-based programs, (7) important components of school programs (guided by the work of Gubbels et al. 2021b), (8) less important components, and (9) other important aspects of school-based child abuse programs. An overview of the results, including the key themes and the corresponding subthemes, is provided in Table 1.

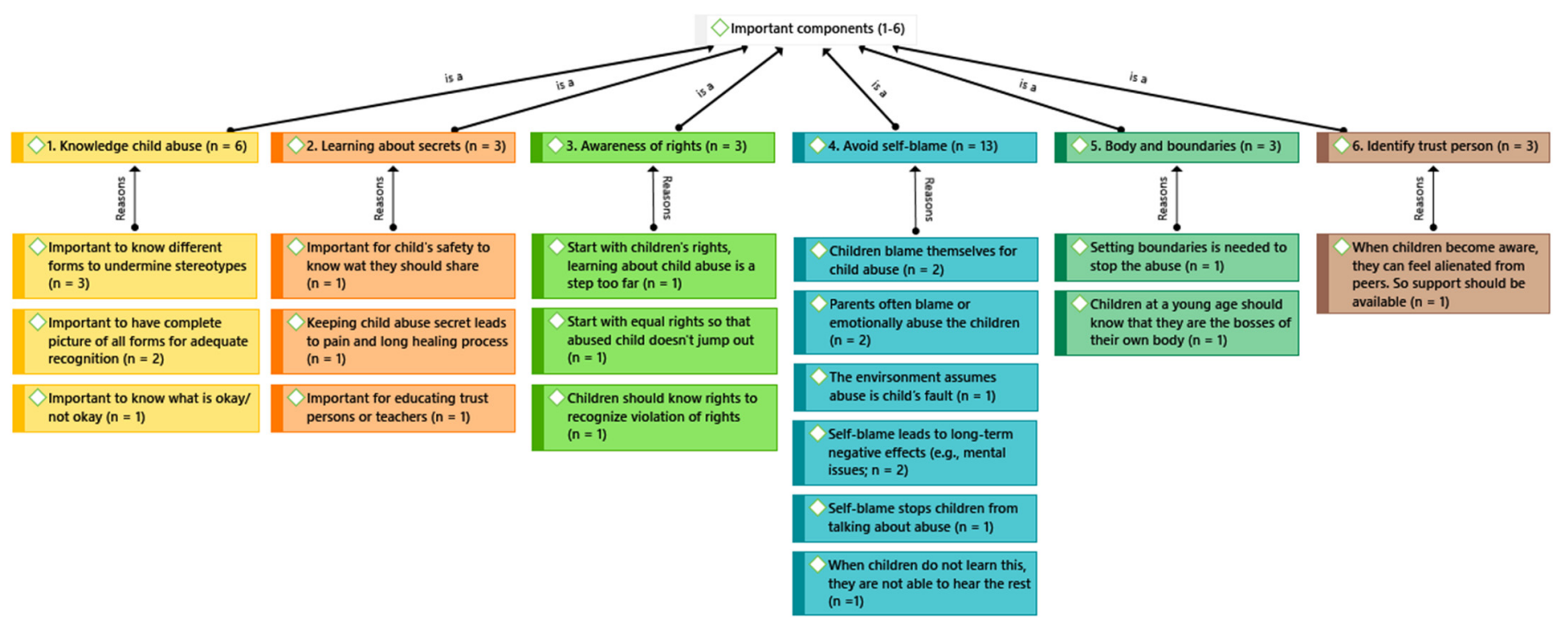

Figure 1. An overview of the results as related to the first set of six components. The labels on the second level refer to the components and the labels on the third level refer to the reasons as provided by the participants for the importance of each component. Yellow labels refer to the components (1) promoting knowledge on child abuse, orange labels to (2) learning about secrets, light green labels to (3) increasing awareness of children's rights, turquoise labels to (4) learning to avoid self-blame, dark green labels to (5) learning about own body and boundaries, and brown labels to (6) identifying trusted persons. $n=$ the number of participants.

Table 1. An overview of the key themes and corresponding subthemes $(N=13)$.

\begin{tabular}{|c|c|}
\hline Key Themes & Subthemes \\
\hline 1. General view & - $\quad$ Positive view $(n=13)$ \\
\hline 2. Goals and positive effects & $\begin{array}{ll} & \text { Increasing awareness / recognition }(n=13) \\
\text { - } & \text { Increasing children's general knowledge }(n=9) \\
\text { - } & \text { Knowing where to find help }(n=8) \\
\text { - } & \text { Knowing you are not alone }(n=5) \\
\text { - } & \text { Disclosure }(n=4) \text { vs. Disclosure not a goal }(n=2) \\
\text { - } & \text { Freaking the taboo }(n=4) \\
\text { - } & \text { Feeling less guilty }(n=3) \\
\text { - } & \text { Early detection and prevention }(n=3) \\
\text { - } & \text { Support from classmates }(n=2) \\
\text { - } & \text { Increasing child's resilience }(n=2)\end{array}$ \\
\hline
\end{tabular}


Table 1. Cont.

\begin{tabular}{|c|c|c|}
\hline Key Themes & \multicolumn{2}{|c|}{ Subthemes } \\
\hline 3. Own experiences & \multicolumn{2}{|c|}{$\begin{array}{l}\text { - } \\
\text { - Wo child abuse education }(n=12) \\
\text { - } \quad \text { One guest lecture on child abuse in high school }(n=1) \\
\text { - How child abuse education could have helped: } \\
\text { - } \quad \text { Sooner recognizing child abuse }(n=13) \\
\text { - } \quad \text { Less self-blame }(n=4) \\
\text { - } \quad \text { Talking about abuse sooner }(n=4) \\
\text { - } \quad \text { More support from teacher and classmates }(n=3)\end{array}$} \\
\hline 4. Effect on knowledge & \multicolumn{2}{|c|}{$\begin{array}{ll}\text { - } & \text { School-based programs increase knowledge }(n=11) \\
\text { - } & \text { Knowledge leads to peer/teacher support }(n=3) \\
\text { - } & \text { Knowledge can prevent child abuse: yes }(n=3) ; \text { no }(n=7) \\
& \text { not sure }(n=3)\end{array}$} \\
\hline $\begin{array}{l}\text { 5. Effect on self-protection } \\
\text { skills }\end{array}$ & \multicolumn{2}{|c|}{$\begin{array}{l}\text { - School-based programs increase skills }(n=7) \\
\text { Skills: telling about abuse }(n=1) \text {, finding help }(n=6) \text {, } \\
\text { dealing with emotions }(n=1) \text {, getting away }(n=1) \text {, saying } \\
\text { 'no' }(n=2) \text {, increasing self-esteem }(n=1) \text {. } \\
\text { - Skills can prevent child abuse: yes }(n=4) \text {; no }(n=6) \text {; not } \\
\text { sure }(n=3)\end{array}$} \\
\hline 6. Potential negative effects & \multicolumn{2}{|c|}{$\begin{array}{l}\text { - } \quad \text { Confrontation has negative effect on child's feelings }(n=8) \\
\text { - } \quad \text { Too much responsibility for the children }(n=5) \\
\text { - } \quad \text { No aftercare }(n=5) \\
\text { - } \quad \text { Nisunderstanding or bullying by classmates }(n=3) \\
\text { - } \quad \text { Children misinterpret information }(n=1)\end{array}$} \\
\hline 7. Important components & \multicolumn{2}{|l|}{ See Figures 1 and 2} \\
\hline \multirow[t]{2}{*}{ 8. Less important components } & - $\quad$ All important $(n=11)$ & \\
\hline & $\begin{array}{ll}\text { 1. } & \text { Knowledge: } n=0 \\
\text { 2. } & \text { Secrets: } n=1 \\
\text { 3. } & \text { Rights: } n=5 \\
\text { 4. } & \text { Self-blame: } n=0 \\
\text { 5. } & \text { Body/boundaries: } n=2 \\
\text { 6. } & \text { Trusted person: } n=1\end{array}$ & $\begin{array}{ll}\text { 7. } & \text { Social skills: } n=4 \\
\text { 8. } & \text { Risk situations: } n=4 \\
\text { 9. } & \text { Assertiveness: } n=3 \\
\text { 10. } & \text { Go away/find help: } \\
& n=1 \\
\text { 11. } & \text { Self-esteem: } n=3 \\
\text { 12. } & \text { Disclose: } n=1\end{array}$ \\
\hline
\end{tabular}

- Much overlap with 12 components $(n=11)$

- Other important components: attachment $(n=1)$, risk factors $(n=1)$, games $(n=3)$, stories abused children $(n=1)$, subgroups (yes: $n=5$; no: $n=2)$, Cross the Line $(n=4)$

- Important conditions: providing after-care $(n=7)$, educating teachers $(n=5)$, creating safe environment

9. Other components $(n=2)$, conditions for schools $(n=2)$.

- $\quad$ Program leader: teacher $(n=9)$, experts $(n=7)$, teacher and expert $(n=3)$, professional and expert $(n=2)$.

- $\quad$ Age of the children: young age $(n=8)$, age 9 or $10(n=4)$, from age of $12(n=1)$.

- $\quad$ Involving parents: yes $(n=3)$, no $(n=4)$, informing $(n=6)$

- Program duration: more than one lesson $(n=10)$, every year $(n=6)$, more intense as children get older $(n=4)$ 


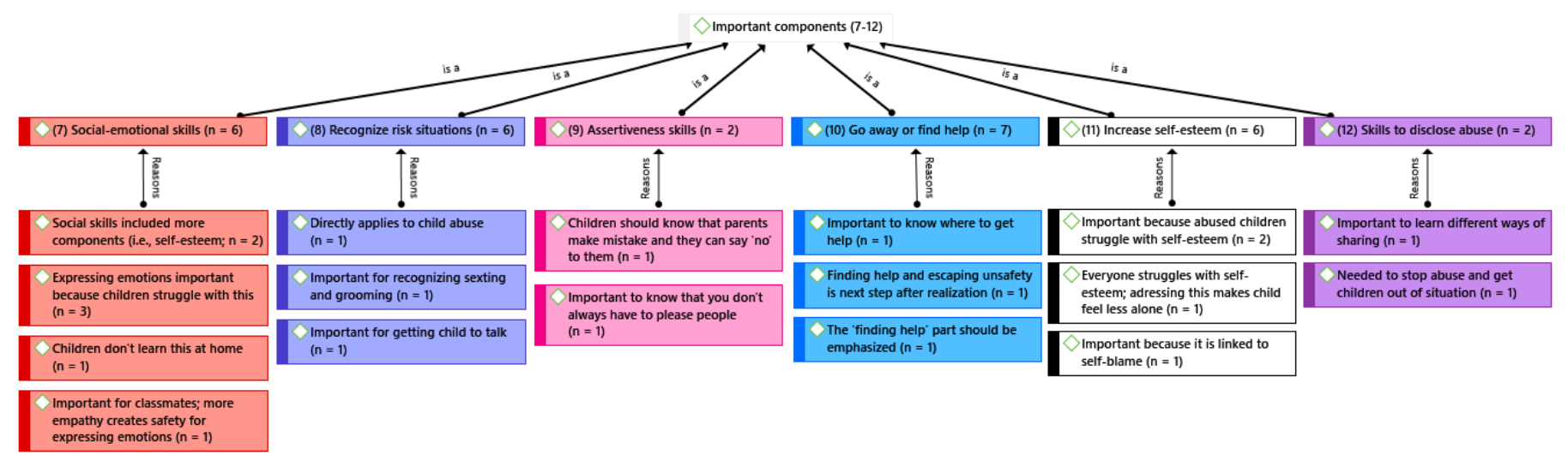

Figure 2. An overview of the results as related to the second set of six components. The labels on the second level refer to the components and the labels on the third level refer to the reasons as provided by the participants for the importance of each component. Red labels refer to the components (7) increasing social-emotional skills, dark blue labels to (8) recognizing and avoiding risky situations, pink labels to (9) increasing assertiveness skills, light blue labels to (10) learning to go away from a potential abusive situation or to find help, white labels to (11) increasing a child's self-esteem, and purple labels to (12) learning skills to disclose abuse. $n=$ the number of participants.

\subsection{General View on School-Based Child Abuse Prevention Programs}

The first question for all participants was how they perceive school-based programs for child abuse prevention. All participants said that it is very important for children to be informed about child abuse at school. One participant said: "I think child abuse education is very important, because in every classroom there is a child who experiences unsafety at home". Being educated about child abuse is considered a children's right. One participant said that, although child abuse education at school is very important, it is a very serious and heavy topic that should be dealt with adequately and in an age-appropriate way.

\subsection{Goals and Positive Effects of School-Based Programs}

Several positive effects of school-based child abuse prevention programs were mentioned. First, it is considered important that children have some general knowledge about what child abuse is (i.e., different forms of abuse) and that children know that different forms of abuse can happen to a child. In that line, four participants said that child abuse education breaks the taboo around child abuse, so that children may feel more free to talk about it. Child abuse education at school can also increase awareness and may help children in recognizing child abuse in their own situation or the situation of their peers. They learn to distinguish between situations that are 'normal' and 'not normal', or that their situation is different than those of their friends. A participant said: "Recognition is very important, because if you grow up in an unsafe environment you don't know any better and you are very loyal to your parents". Recognition can be immediate, however, a school program can also cause realization later on by planting a seed in the minds of young children. Several participants even suggested that the sooner children realize that their situation is unsafe or abusive, the sooner further steps can be taken to stop the abuse after which help for parents and the child can be organized. Additionally, participants mentioned that important goals of school-based child abuse prevention are that children know what to do, how to report and where to find help in case of unsafety, and to detect signs with their peers.

According to the participants, school-based programs may lead to an early detection and prevention of child abuse, which could lead to less costs for society. Further, schoolbased programs may create opportunities to talk about child abuse and encourage children to disclose and tell people about potential child unsafety or abuse. However, two participants felt that disclosing child abuse should not be the main goal of child abuse prevention programs at school, because a child should not be forced to talk about child abuse. They explained that it is more important to inform children about safety and what to do when 
their situation is not safe. Participants also mentioned that child abuse prevention programs may lead to better understanding and support of classmates regarding the situation of abused or neglected children, and therefore to less bullying. Two participants viewed child abuse education as a protective factor and a way to increase children's resilience. Five participants expressed that child abuse education may contribute to less loneliness: children in abusive situations may realize that they are not alone and that other children experience the same problems at home. Children may also feel less guilty, and relieved and acknowledged after attending a school-based prevention program. One participant said: "I think children would feel relieved because there finally is attention for the topic of child abuse at school and finally feel that they are being seen and heard".

\subsection{Own Experiences with School-Based Programs}

Only one participant reported having experiences with child abuse education, in the form of a high school guest lecture about child abuse. The participant remembered that there was an exercise about self-value and ways to express emotions. The participant was positive about the interactive part of the lecture, during which topics were discussed in small groups of two or three students. However, the participant mentioned that the lecture was not taken seriously by the participant's classmates and that the class was not prepared for such a sensitive topic. The participant said: "I did not feel very good afterwards. My classmates were laughing during the lecture and not taking it seriously. That made me feel like they didn't really care and my situation didn't matter".

Of the 12 participants who did not receive any child abuse education, 11 would have wanted to be educated about child abuse at school. One participant was not sure, as too much responsibility may be put on children whereas parents or caretakers should bear responsibility for any episode of child abuse. The participant continued elaborating that abused children being educated may make them feel like an outsider. When we asked the participants what school-based child abuse education could have meant in their own situation, several positive outcomes were mentioned. All participants expressed that they would have recognized the abuse sooner. One participant stated: "I really would have wanted child abuse education so that I sooner realized that I was being abused and knew that my situation was not normal. Then I would have talked sooner and the abuse would have stopped sooner. That is better than the hell that I have gone through the last couple of years". Participants also suggested that they would have been less hard on themselves or feel less self-blame if they had received education about child abuse at school. Some participants said that education may have also triggered them to talk about the abuse or that they would have felt more comfortable in talking about their situation. Three participants said that school-based child abuse programs increase the understanding and support of teachers and classmates towards abused children and make them aware of what to do when a peer is abused. Finally, child abuse education at school and learning that the abuse is not a child's fault might decrease the long-term negative effects on the child's mental health. A participant stated: "I think that if I'd heard as a kid that it wasn't my fault, I wouldn't be needing trauma treatment right now".

\subsection{Effect of School-Based Programs on Knowledge}

Most participants agreed that school-based child abuse prevention programs have positive effects on a child's knowledge and the ability to recognize abusive situations. It is important that children know different signs of child abuse in order to detect abuse in either their own situation or that of a peer. One participant mentioned: "When a child experiences abuse, he or she does not know what is happening. If they receive at least some information about child abuse than they know: 'OK, this is something that can actually happen to me'". Three participants mentioned that this child abuse-related knowledge can lead to more support and empathy from classmates and the teacher.

Three participants said that more child abuse related knowledge can prevent child abuse or further deterioration of already unsafe situations. For example, this knowledge 
could lead to the detection of child abuse signs, causing children to alert someone sooner or ask for help. One participant said that peers become more alert for signs and become more supportive, providing children with a social safety net. Seven participants did not think that more knowledge could entirely prevent child abuse, because parents or perpetrators are the ones responsible for the abuse. A participant said about this: "Only providing children with knowledge is not enough, because children cannot stop the violence or abuse on their own. You need the parents and other adults for that. So, we should not solely focus on the child, but instead on the whole social environment surrounding the child". Other participants were not sure whether or not child abuse could be prevented through more child abuse related knowledge.

\subsection{Effect of School-Based Programs on Self-Protection Skills}

We asked participants whether school-based programs contribute to increasing children's self-protection skills, including asking for help or standing up for yourself. Seven participants agreed that school-based child abuse prevention programs can have positive effects on children's self-protection skills. Other participants mentioned that this depends on whether the program specifically targets self-protection skills and what skills were targeted. Participants mentioned several skills that should be addressed in the schoolbased programs, including skills for talking about potential abuse, finding help, dealing with emotions, getting away from abusive situations, learning to say 'no', and skills for increasing the child's self-esteem. Two participants mentioned that assertiveness skills, such as learning to say 'no', should not be addressed in school-based prevention programs: "I think that increasing the resilience of children and learning to say no can work in anti-bullying programs, but not in child abuse prevention. There is a specific balance of power between the child and the perpetrator, so forcing against the perpetrator or parent does not really change anything".

Four participants agreed that children's self-protection skills could prevent child abuse, as these skills include disclosing the abuse to someone who might end the abuse. Self-protection skills might also include dealing with the abuse and decreasing the longterm negative effects. Regarding this, a participant mentioned: "Violence often gets worse. The longer it lasts, the more persistent it becomes. Children can be the ones who break the cycle of violence if they dare to tell someone about it. Also, if children acknowledge that they have experienced child abuse, they are more likely to seek help or go to a therapist later in life. This will decrease the chances for intergenerational transmission of child abuse". Six participants didn't think that child self-protection skills can prevent child abuse, as it is caused by the parent and other external stressors, on which the children do not have influence. They specified that, in order to prevent child abuse, detection should be emphasized. Three participants were not sure about whether or not child abuse could be prevented through teaching children self-protection skills. They indicated that it is especially important to provide support to children and make sure that there is someone to talk to.

\subsection{Potential Negative Effects of School-Based Programs}

Regarding potential negative effects of school-based child abuse education, most participants indicated that the confrontation or realization that may arise from schoolbased child abuse education will negatively affect children in the short-term. Children may experience loneliness given their situation, become an outsider, or may feel alienated from their parents. Confrontation by attending a school program might also lead to confusion and potential re-traumatization. One participant said: "When I look back, things were really bad at my house, but I was in survival mode, so it didn't really get to me. Child abuse education would have hold up a mirror for me and pulled me out of that survival mode, which possibly would have made me feel worse".

Participants also mentioned that children are not the ones responsible for their situations, which contrasts with the child-focused nature of school-based prevention programs. Five participants thought that school-based abuse prevention programs could have negative effects when no care or support is provided by the school or teachers after the program. Further, although children need support from their peers, children might feel alienated 
from their classmates, causing them to feel misunderstood or to become a victim of bullying. Two participants also mentioned the potential negative effect of saying no or setting boundaries towards parents: "If a child suddenly says ' $n o$ ' to their abusive parent, this can backfire because it causes friction and might lead to the parent hitting the child even more". Finally, one participant worried that the children might misinterpret the information provided in the program, because they do not listen very well or have a hard time concentrating.

\subsection{Important Components of School-Based Programs}

The results presented below include the reflections of the participants on specific program components that were extracted from the work of Gubbels et al. (2021b). As described in the Method section, we divided the components into two sets and, per set, we asked the participant which components they viewed as most important. Figures 1 and 2 present the results for both sets of components.

\subsubsection{Knowledge on Child Abuse and Prevention Concepts of Definitions}

Six participants viewed gaining knowledge on child abuse or prevention-related concepts as one of the most important components. According to participants, it is important for children to learn that child abuse is not just kicking and hitting or some other physical actions causing children to end up in a hospital. Learning about the different forms of child abuse could help in tackling these stereotypes. Two participants said that having this knowledge is especially important so that all abused or neglected children can recognize themselves, no matter the form of child abuse: "You have to give a complete picture of all the forms of abuse, otherwise not all children will recognize the specific form of abuse they are experiencing". In this light, some participants mentioned that it might be better to use the term child unsafety instead of child abuse. This component was also viewed as important as it helps children in knowing which situations are acceptable and not acceptable.

\subsubsection{Learning about Safe and Unsafe Secrets}

Three participants emphasized the importance for school-based programs to focus on learning about safe and unsafe secrets (i.e., secrets that are okay or not okay to keep). For the child's safety, it was considered important to know what they can and should share. One young adult said: "For me this would have been very important because I kept my situation a secret for a very long time. And the longer you keep it a secret the longer the pain and process of healing". Learning about safe and unsafe secrets was also considered important in the education for teachers and trust persons. When a child comes to them with a secret, they should always say that it cannot always stay a secret. One participant said: "Eventually it must come out in order for the child to get help".

\subsubsection{Increasing Awareness of Children's Personal Rights}

Three participants indicated that learning about children's personal right, such as the right to be safe or the right over their own body, is a very important component. The programs should start with these rights, partially because starting with child abuse might be a step too far for children. One participant said: "You should start with saying that everyone has equal rights, without any exception. If you start with educating about child abuse, the abused child immediately feels different and jumps out, which is something you don't want". Further, it was also mentioned that children often do not know that they have rights. Learning this is needed for children to recognize when their rights are violated.

\subsubsection{Teaching Children to Avoid Self-Blame and That Abuse Is Never a Child's Fault}

All participants agreed that teaching children that they are never to blame in abusive situations is one of the most important components of school-based programs. According to the participants, children often feel very guilty and blame themselves for their situation. They are often also blamed by their parents and other people in their environment. Learning that abuse is not a child's fault is needed to get children to talk about potential abuse and 
to stop ongoing abuse. A participant said: "It took me a long time before I realized it wasn't my fault. I think my situation could have stopped sooner if I knew earlier that it wasn't my fault". Two participants mentioned that learning to avoid self-blame could reduce the long-term negative effects of child abuse, including depression and other mental health problems. A participant mentioned: "I still suffer from my past because no one ever told me it wasn't my fault. I truly believe that if I didn't experience self-blame, I would have had less issues now". Another participant said that this component should be the core of school-based education. When abused children do not learn this, they are not able to hear the rest.

\subsubsection{Learning about Own Body and Boundaries}

Three participants viewed learning about your own body and boundaries, such as the difference between safe and unsafe touches, as a core component of school-based programs. Setting boundaries was considered essential in stopping the abuse, and at a very young age children should learn that they are 'the bosses' of their own body. A participant said: "A child should just know from an early age: 'This is my body and no one can touch it without me wanting to'".

\subsubsection{Identifying a Trusted Person}

Three participants thought that one of the most important components of a schoolbased program is to identify trusted persons for children, such as people in school or family members, and building a community support system around the child. Support and trusted persons are important because, when children become aware of the abuse, they can feel alienated from their peers. As they cannot talk about it at home, support should always be available.

\subsubsection{Increasing Social-Emotional Skills}

Increasing social-emotional skills of children, such as empathy with peers, social problem-solving skills, or expressing emotions, was considered a very important component by six participants. Two participants indicated that this component includes multiple important aspects and overlaps with other components, such as increasing self-esteem, asking for help, or standing up for yourself. Three participants thought that especially learning to express emotions is very important during school-based programs, because they struggled with this. One participant said: "Learning how to express emotions would have helped me because I didn't know what to do with my emotions or where to turn to. So, I put them away and closed myself off from my emotions. I built a wall around myself". Furthermore, it was mentioned that not talking about emotions leads to long-term distress and that learning social-emotional skills is important because abused children often don't learn this at home. Finally, this component was considered important for both maltreated children and for their classmates. If classmates learn how to be empathetic, children might feel safer to express their emotions.

\subsubsection{Recognizing and Avoiding Risky Situations}

Six participants viewed recognizing and/or avoiding risky situations, such as abusive situations or potential abusers, as an important component of school-based programs. This component directly applies to child abuse, whereas some of the other components, such as learning social-emotional skills or assertiveness skills, are more broadly applicable. Another participant indicated that this component is especially important in recognizing (perpetrators of) sexting and grooming. These forms of abuse should not be a taboo and children should be educated about this. Finally, this component was considered important for getting children to talk about the abuse. One participant mentioned: "If you don't know that you are dealing with abuse, you cannot talk about it". 


\subsubsection{Increasing Assertiveness Skills}

Increasing assertiveness skills, such as saying 'no' and standing up for yourself, during school-based programs was viewed as very important by two participants. Children have to learn that their parents make mistakes and that they can say "no" to them. One participant said: "Learning to stand up for myself would have been very important to me. I could never say 'no', always wanted to please people and was afraid of doing something wrong. For children, it is important that they learn this".

\subsubsection{Learning to Go Away from Abuse or to Find Help}

Seven participants found it important that learning to go away or find help was addressed in school-based programs, especially knowing that children can get help and where they can get it (e.g., the child abuse hotline, child protection services, going to neighbors or family). Children often do not know which options there are when they grow up in unsafety. Further, after children realize that they are abused, finding help and escaping from unsafety is often the next step. One participant mentioned that, in this component, the part about finding help should be emphasized, because going away from a situation is very difficult when there is no help or support.

\subsubsection{Increasing Children's Self-Esteem}

Six participants agreed that increasing children's self-esteem is an important component. One participant said: "I think that everyone who experienced childhood abuse or neglect has a low self-esteem. I am still struggling with this, despite all the therapy". Other participants also mentioned that this component is very important for children in general, and that all children or adolescents struggle with self-esteem, whether they experienced child abuse or not. Therefore, addressing self-esteem in school-based programs may cause abused children to feel less lonely or different. One participant said that this is an important component because it is linked to self-blame and learning that child abuse is not a child's fault.

\subsubsection{Learning Skills to Disclose Abuse}

Finally, two participants suggested that learning skills to disclose child abuse is very important in school-based programs, such as encouraging children to report abuse to trusted adults or developing the vocabulary needed to report. This was considered an important component because this is needed to stop the abuse in the short-term and to remove a child from an abusive situation. Further, one participant said that it is important to learn different ways to disclose: "I think this component should consist of different ways of sharing something about your situation. If you are afraid to talk about is, other ways of sharing should be available. Everything should be aimed at lowering the threshold for children to share that something is wrong".

\subsection{Less Important Components}

We also asked the participants if there were components that they viewed as less important or least important. Most participants mentioned that all 12 components were important to include in school-based programs. Learning about the rights of children was most often marked as being the least important component. One noted: "Children's rights are constantly violated in case of child abuse, so I don't see the point in learning those". Another participant mentioned that children's rights might not apply directly to child abuse and are therefore less important in school-based preventions programs. This was also one of the reasons mentioned by participants who view learning about social skills and self-esteem as least important. Other reasons for social skills to be less important were that children often already have these skills, learning to empathize with abused children might be too heavy for young children, and that this component is already taught at school. Finally, four participants indicated that learning to recognize risky situations is less important, because abused children already know this. One participant said: "This component might lead to the child feeling unsafe in relatively safe situations because the child becomes oversensitive to unsafety". 


\subsection{Other Important Aspects of School-Based Programs}

Participants were also asked if there are other important components or aspects that should be addressed in school-based programs, aside from the 12 components as described by Gubbels et al. (2021b). Many of the aspects overlapped with the 12 components described above, such as discussing the different forms of child abuse (i.e., child sexual abuse, children who have to take care of their parents), how to recognize and deal with emotions, knowing where to find help, identifying trusted persons, and learning how to talk with teachers. Additionally, the following components and aspects were mentioned: learning about safe and unsafe attachment; discussing risk factors for child abuse, such as poverty and parental addiction; teaching the program core concepts through games or in other creative ways (e.g., drawing, singing, movies); hearing stories from other children or adolescents who experienced abuse. Five participants indicated that dividing the children into subgroups might be a good context for teaching children certain self-protection skills. On the other hand, two participants thought that the class should not be divided into subgroups during the program to prevent children from feeling excluded or isolated. Finally, four participants suggested 'Cross the Line' as a helpful exercise in which children are asked to stand on one side of a room and step over a line when a certain statement applies to them (see for example Higgins 2008). A participant said about this: "In this way, children might find out that they are not the only one in their situation".

Participants also mentioned several conditions for implementing school-based prevention programs. Seven participants said that it is important to provide children with after-care or make sure that there is someone a child can talk to about potential abuse: "It should be clear for children where they can turn to and who is available to talk to". Another important condition was that teachers receive education about detecting and handling child abuse and that they are prepared for potential disclosures. Further, participants indicated that it was important to create a safe environment before implementing a prevention program in the classroom and that several conditions were met in the schools, including a protocol for reporting child abuse.

Participants also gave their opinion on who should lead the school-based programs, the age of children, whether parents should be involved, and the program duration or intensity.

\subsubsection{Program Leader}

Nine participants thought that school-based child abuse prevention programs should be led by the classroom teachers, because they know the children and the children know them. Furthermore, teachers can provide pre- and after-care and they are in a good position to detect signs. Seven participants said that school programs should be led by experts who experienced child abuse (like themselves), as they can talk from their own experience and know how to talk to children. Abused children might also feel less alone when they know that there were other people in their situation. Three participants agreed that the lessons should be provided by a combination of teachers and victim experts, partially to take away some of the burden for teachers. Two participants suggested a combination of a professional with a relevant background (e.g., social worker, psychologist) and a victim expert.

\subsubsection{Age of the Children}

Most participants agreed that child abuse education should starts at a very young age, and as soon as possible. The child abuse education for young children should be very basic and simple, using simple stories or puppets. It should be interactive and mainly focus on learning about boundaries. Four participants thought that the age of 9 or 10 years is a good age to start with child abuse education. A participant said: "I don't think that I would have listened before the age of 9" and another participant said: "I would not have understood it at a younger age". One participant suggested the age of 12 years. 


\subsubsection{Involving Parents}

Three participants agreed that parents should be involved in the school-based program. One participant thought that this is an important condition for implementing a schoolbased program. This participant said: "You want everyone to support the children. When we educate children about child abuse, we have to be there for them and be able to act immediately if that is necessary. This also refers to the parents", Including parents is also considered important because parents are often the perpetrators of child abuse and therefore the ones you can influence. Four participants indicated that it is better not to include parents in the child abuse program, because this might be unsafe for children who are being abused. The rest of the participants agreed that parents should at least be informed about the school program, for example through an information letter or a parent meeting.

\subsubsection{Program Duration or Intensity}

Most participants thought that school-based programs should include at least more than one lesson to be effective in addressing child abuse. Six participants agreed that lessons about child abuse should be repeated every year to keep reminding children what they learned. Four participants said that the program should be more intense (more lessons) as the children get older, because children understand more when they are older.

\section{Discussion}

This study examined the perspectives of young child abuse survivors on essential components in school-based child abuse prevention programs. To this end, 13 young adults with a history of childhood abuse or neglect victimization were interviewed to gain insight into their experiences with school-based programs, and their view on how these programs should be shaped and which program components should be addressed in school-based programs. For the latter, a list of 12 program components was used, extracted from the work of Gubbels et al. (2021b). Below, the most important findings as related to the key themes are discussed. Also, the current results are compared to the findings of Gubbels et al. (2021b) to review to what extent the programs components designated as important by the young adults contribute to the effectiveness of school-based prevention programs.

Although only one participant attended some form of school-based child abuse education, we found that child abuse education was considered very important by the young adults. This is in line with findings of a recent study in the Netherlands indicating that school-based child abuse prevention programs are hardly implemented in Dutch primary schools (Gubbels et al. 2021a). Gubbels and colleagues approached 84 primary schools, of which only one school had implemented a yearly child abuse prevention program. They found that this is partially due to the fact that child abuse education is often not part of the standard curriculum of primary or secondary schools, as child abuse is a sensitive topic and there are many more topics to be discussed at school, such as alcohol or drug abuse (Gubbels et al. 2021a). The lack of school-based programs for the prevention of child abuse is a global issue and is seen in various countries all over the world (World Health Organization 2014, 2018). In the United States, however, school-based programs for child sexual abuse prevention are widely adopted as state and federal laws require public schools to implement child-focused child sexual abuse victimization prevention efforts (Bernier 2015; Finkelhor et al. 1995). In contrast, there are no laws in the Netherlands requiring schools to implement child abuse prevention programs, which might explain the lack of attention paid to child abuse in Dutch schools.

The positive effects of school-based child abuse prevention programs that were mentioned by the young adults are in line with the general aim of school-based prevention programs, which is to prevent child abuse by providing children with child abuse-related knowledge and self-protection skills that decrease a child's risk for abuse, and by encouraging disclosure of potential abuse which is needed to stop ongoing abuse (Blakey and Thigpen 2015; Ko and Cosden 2001). Furthermore, review studies showed significant effects of school-based 
prevention programs on knowledge, self-protection skills, and disclosure (Davis and Gidycz 2000; Gubbels et al. 2021b; Rispens et al. 1997; Walsh et al. 2018).

A potential negative effect of school-based programs was that children could suffer from re-traumatization after realizing that they are or have been abused or neglected, especially when no care or support is provided after the program by teachers or other school staff. The importance of adequate aftercare in the period following the program was also pointed out in previous studies on experiences of child abuse survivors with support at school (Frederick and Goddard 2010; Schönbucher et al. 2014). Social support during or after child abuse can considerably alleviate negative repercussions for mental health, has a buffering effect against trauma, and facilitates a child's adaptive coping (Marivate and Madu 2007; Yancey and Hansen 2010).

The interviewed participants are on the same page as critics who have argued that abuse prevention cannot be prevented or deterred by the actions of children themselves, as children are too weak and too vulnerable to resist perpetrators who are often older, larger, and aggressive (Finkelhor 2007). However, Finkelhor (2007) noted that schoolbased prevention-education programs have additional, important objectives beside those of preventing victimization, including promoting the reporting of victimization, reducing the stigma and self-blame that victimized children feel, and educating parents, teachers, and other community members about the problem.

Many program components that were considered important in school-based programs by the interviewed young adults are also pointed out as essential or effective components in the literature. For example, teaching children that they are never to blame in abusive situations is associated with better effects of school-based programs on children's child abuse-related knowledge (Gubbels et al. 2021b). Child abuse often results in self-blaming or a pessimistic attributional style, possibly due to internalizing parental (or others who inflict child abuse) negative beliefs about them (Carlson et al. 1997; Messman-Moore and Coates 2007). Therefore, it may be important to address self-blame in school-based programs. Feelings of guilt and shame among abused children also reduce their likelihood of abuse disclosure (Azad and Leander 2015; Schönbucher et al. 2012).

Further, Gubbels et al. (2021b) found that effects on children's child abuse knowledge were larger in school-based programs addressing social-emotional skills (including skills regarding social relationships, empathy, emotion management, and problem-solving) compared to programs not addressing these skills. They argued that these skills enable children to empathize with others who are in abusive situations, which may increase their knowledge on abuse concepts (Gubbels et al. 2021b). Increased social problem-solving skills also enable children to offer more thoughtful solutions to different situations, and therefore to better resolve child abuse-related dilemmas (Grober and Bogat 1994; Sanderson 2004).

The program components "learning to escape abusive situations or find help", "increasing child abuse related knowledge", "recognizing risky or potentially abusive situations", and "increasing children's self-esteem" were not significantly associated with the effectiveness of school-based prevention programs (Gubbels et al. 2021b). However, the literature points out that escaping potential abusive situations and seeking help from trusted adults or institutions are core concepts in the curricula of school-based prevention programs (MacIntyre and Carr 2000; Topping and Barron 2009). Walsh et al. (2018) argued that school-based child abuse prevention programs endeavor to minimize harm by disseminating messages about appropriate help seeking in the event of abuse or attempted abuse. Further, learning about and recognizing different types of child abuse is an important theme in many school-based child abuse prevention programs, as it is needed for children to respond to or report abusive situations (Blakey and Thigpen 2015; Topping and Barron 2009).

As for the component "increasing children's self-esteem", it was found that abused children have lower self-worth than their peers (Burack et al. 2006) and low self-esteem causes feelings of guilt and shame among abused children (Dorahy and Clearwater 2012; Jonas et al. 2011). This indicates the importance of addressing self-esteem in school-based programs. Because self-esteem may be related to better use of protection behavior when 
children are confronted with scenarios of sexual abuse, physical abuse, and stranger danger (Brassard and Fiorvanti 2015; Fryer et al. 1987), programs may need to attend to the level of self-esteem in children as an indicator of which children may need more assistance in learning protection skills or how to use them.

Further, the importance of teaching the program's core concepts through games or in other creative ways was also pointed out by Gubbels et al. (2021b). They found a significant moderating effect of using games in school-based programs for increasing abuse-related knowledge. Games have a positive impact on students' learning, as they increase their motivation, confidence, effort, and involvement in their learning (Scholes et al. 2014).

Davis and Gidycz (2000) found that school-based programs that encourage the active participation of children through games and role-plays are more effective than those that use either passive methods (e.g., traditional teaching, discussions) or no participation (e.g., written materials).

Teachers and victim experts were considered to be suitable program leaders by the young adults. No significant moderating effect was found for the type of program instructor in previous review studies (Davis and Gidycz 2000; Gubbels et al. 2021b). Other research is divided about who should deliver child abuse education at school. Berrick and Barth (1992) indicated that teachers are in a good position to educate children about potential abuse, while Barron and Topping (2013) found that, when survivors of abuse presented a school-based child sexual abuse prevention program, higher levels of disclosure occurred compared with teachers. Barron and Matthew (2014) suggested that future school-based child abuse programs should be delivered by adult survivors alongside teachers, as they held different beliefs about the delivery and impact of the programs and could therefore complement each other.

Further, young child abuse survivors agree that school-based child abuse education should start at a very young age. This is in line with research findings indicating that younger children benefit more from school-based child abuse prevention programs than older children (Davis and Gidycz 2000; Gubbels et al. 2021b; Rispens et al. 1997), underlining the importance of applying a preventive approach to child abuse. The young adults also advised including, or at least informing, parents about the school-based program and that the lessons of the programs should be repeated regularly. Again, these results are consistent with those of the previous review studies on the effect of school-based child abuse prevention programs (Davis and Gidycz 2000; Gubbels et al. 2021b; Kenny et al. 2008; MacIntyre and Carr 2000; Rispens et al. 1997; Topping and Barron 2009).

Some limitations of this study need to be mentioned. First, a relatively small number of young adults were interviewed. Therefore, the generalizability and ecological validity of the study findings might be limited. However, it has been recommended that qualitative studies require a minimum sample size of at least 12 participants to reach data saturation (Clarke and Braun 2013; Fugard and Potts 2015; Guest et al. 2006). Furthermore, in the literature it is argued that qualitative research often concerns developing a depth of understanding rather than a breadth, and that a sample size of one can even be highly informative and meaningful, particularly when undertaken under a non-positivist paradigm (Boddy 2015, 2016). Therefore, a sample of 13 was deemed sufficient for the qualitative analysis and scale of this study. Second, we sampled victimized young adults who were willing to participate voluntarily in this study and were affiliated with two Dutch child abuse organizations. These young people regularly share their experiences at conferences and give advice to policymakers, politicians, and researchers. They are probably more motivated and interested in sharing their opinions on the prevention of child abuse than the average child abuse survivor. Therefore, selection bias might be present in our data, which should be taken into account when interpreting the current findings. However, it should be noted that, as child abuse victimization is a traumatic experience with long-lasting effects, it might not have been easy to find other survivors who were willing to talk about their experiences and share their thoughts on child abuse prevention. Finally, due to cultural 
differences, it is uncertain whether the results of the current study, using a Dutch sample, is generalizable to samples from other countries.

The current results provide important knowledge for clinical practice and suggestions for future research. First, as mentioned before, the results of the current study and of previous research (Gubbels et al. 2021a; World Health Organization 2014, 2018) may indicate a lack of child abuse education at schools. The sample size of our study does not allow drawing strong inferences on how child abuse prevention should be shaped and implemented, however, it does give first insights into the importance of child abuse prevention programs in schools to increase children's knowledge and skills. Here, young adults consider it important that, after the prevention program, an adequate support or care system is available at the school to support children who experience(d) abuse or neglect. Furthermore, introducing national legislation or policy on child abuse education in Dutch schools may promote the implementation of school-based programs.

Furthermore, in developing future school-based programs or improving existing programs, the young child abuse survivors suggested that it is important to focus on several program components. These included teaching children that abuse is never the child's fault, learning to go away or find help, increasing children's social-emotional skills, promoting child abuse-related knowledge, recognizing risky situations, and increasing children's self-esteem. In previous research, these programs components were also found to be effective or relevant in the prevention of child abuse (Gubbels et al. 2021b; Topping and Barron 2009; Walsh et al. 2018). These components should therefore be considered in improving or developing school-based programs.

Finally, studies examining the effect of school-based programs are often solely focused on programs for the prevention of sexual abuse (Blakey and Thigpen 2015; Gubbels et al. 2021b). However, the young child abuse survivors indicated that school-based programs are needed for preventing child abuse in general, and found it very important to teach children about all forms of child abuse. Furthermore, sexual abuse is the least prevalent form of child abuse (Stoltenborgh et al. 2015). Therefore, future experimental research may focus on examining the effectiveness of school-based prevention programs for all forms of child abuse, including physical abuse, emotional abuse, and neglect.

\section{Conclusions}

The young child abuse survivors that were interviewed in the current study consider child abuse prevention at school very important for increasing children's awareness of abuse in the (family) situation of their own or in that of peers, and for teaching children skills to reduce the risk of child abuse. Following these perspectives, schools in the Netherlands may consider implementing school-based child abuse prevention programs more often. In shaping future school-based programs, or in improving existing programs, the young child abuse survivors suggested that children should be taught that they are never to be blamed for abusive situations and where they can find help in potential abusive situations. Finally, young child abuse survivors find it very important to provide children with adequate aftercare when school-based prevention programs end.

Author Contributions: Conceptualization, C.E.v.d.P. and J.G.; methodology, C.E.v.d.P. and J.G.; validation, J.G., C.E.v.d.P. and M.A.; formal analysis, J.G.; investigation, J.G.; resources, C.E.v.d.P.; writing—original draft preparation, J.G.; writing—review and editing, C.E.v.d.P., P.P., M.A. and J.G.; supervision, C.E.v.d.P., P.P. and M.A.; project administration, C.E.v.d.P.; funding acquisition, C.E.v.d.P. All authors have read and agreed to the published version of the manuscript.

Funding: This research was funded by ZonMw, grant number 741100002.

Data Availability Statement: Not applicable.

Conflicts of Interest: The authors declare no conflict of interest. 


\section{References}

Archibald, Mandy M., Rachel C. Ambagtsheer, Mavourneen G. Casey, and Michael Lawless. 2019. Using Zoom Videoconferencing for Qualitative Data Collection: Perceptions and Experiences of Researchers and Participants. International Journal of Qualitative Methods 8: 1-8. [CrossRef]

Asawa, Lindsey E., David J. Hansen, and Mary Fran Flood. 2008. Early childhood intervention programs: Opportunities and challenges for preventing child maltreatment. Education \& Treatment of Children 31: 73-110. [CrossRef]

Augeo. 2018. Praten over wat je thuis meemaakt [Talking about What You Experience at Home]. Driebergen-Rijsenburg: Augeo Foundation, Available online: https:/ / www.augeo.nl/-/ media/Files/181119-Praten-over-wat-je-thuis-meemaakt.ashx (accessed on 14 July 2021).

Azad, Azade, and Lina Leander. 2015. Children's Reporting about Sexual Versus Physical Abuse: Patterns of Reporting, Avoidance and Denial. Psychiatry, Psychology and Law 22: 890-902. [CrossRef]

Barron, Ian G., and Keith J. Topping. 2013. Exploratory Evaluation of a School-Based Child Sexual Abuse Prevention Program. Journal of Child Sexual Abuse 22: 931-48. [CrossRef]

Barron, Ian G., and Laurie Matthew. 2014. A preliminary evaluation of presenter effects in the delivery of abuse prevention interventions: Teacher and survivor perspectives. Educational E Child Psychology 31: 42-54.

Bernier, Jetta. 2015. State and Federal Legislative Efforts to Prevent Child Sexual Abuse: A Status Report. Chicago: Prevent Child Abuse America, Available online: http:/ / preventchildabuse.org/images/docs/PCA_MK_CSAstatusreport.pdf (accessed on 6 September 2021).

Berrick, Jill Duerr, and Richard P. Barth. 1992. Child sexual abuse prevention: Research review and recommendations. Social Work Research $\mathcal{E}$ Abstract 28: 6-15. [CrossRef]

Blakey, Joan M., and Jeffry W. Thigpen. 2015. Play it safe! ${ }^{\circledR}$ : A school-based childhood physical and sexual abuse prevention program. Journal of Adolescent and Family Health 7: 5.

Boddy, Clive R. 2015. Psychopathic leadership: A case study of a corporate psychopath CEO. Journal of Business Ethics 145: 141-56. [CrossRef]

Boddy, Clive R. 2016. Sample size for qualitative research. Qualitative Market Research 19: 426-32. [CrossRef]

Boeije, Hennie. 2009. Analyseren in kwalitatief onderzoek: Denken en doen [Analyzing in Qualitative Research: Thinking and Doing]. Amsterdam: Boom Lemma Uitgevers.

Brassard, Marla R., and Christina M. Fiorvanti. 2015. School-based child abuse prevention programs. Psychology in the Schools 52: 40-60. [CrossRef]

Burack, Jacob A., Tara Flanagan, Terry Peled, Hazel M. Sutton, Catherine Zygmuntowicz, and Jody T. Manly. 2006. Social perspectivetaking skills in maltreated children and adolescents. Developmental Psychology 42: 207-17. [CrossRef]

Carlson, Eve B., Lita Furby, Judith Armstrong, and Jennifer Shlaes. 1997. A conceptual framework for the long-term psychological effects of traumatic childhood abuse. Child Maltreatment 2: 272-95. [CrossRef]

Cicchetti, Dante. 2016. Socioemotional, personality, and biological development: Illustrations from a multilevel developmental psychopathology perspective on child maltreatment. Annual Review of Psychology 67: 187-211. [CrossRef]

Clarke, Victoria, and Virginia Braun. 2013. Successful Qualitative Research: A Practical Guide for Beginners. London: Sage.

Davis, M. Katherine, and Christine A. Gidycz. 2000. Child sexual abuse prevention programs: A meta-analysis. Journal of Clinical Child Psychology 29: 257-65. [CrossRef] [PubMed]

Dhooper, Surjit Singh, and Phyllis L. Schneider. 1995. Evaluation of a school-based child abuse prevention program. Research on Social Work Practice 5: 36-46. [CrossRef]

Dorahy, Martin J., and Ken Clearwater. 2012. Shame and guilt in men exposed to childhood sexual abuse: A qualitative investigation. Journal of Child Sexual Abuse 21: 155-75. [CrossRef]

Finkelhor, David, Nancy Asidigian, and Jennifer Dziuba-Leatherman. 1995. Victimization prevention programs for children: A follow-up. American Journal of Public Health 85: 1684-89. [CrossRef]

Finkelhor, David. 2007. Prevention of sexual abuse through educational programs directed toward children. Pediatrics 120: 640-45. [CrossRef]

Frederick, John, and Chris Goddard. 2010. 'School was just a nightmare': Childhood abuse and neglect and school experiences. Child E Family Social Work 15: 22-30. [CrossRef]

Fryer, George E., Sherryll K. Kraizer, and Thomas Miyoshi. 1987. Measuring children's retention of skills to resist stranger abduction: Use of the simulation technique. Child Abuse E Neglect 11: 181-85.

Fugard, Andy, and Henry W. W. Potts. 2015. Supporting thinking on sample sizes for thematic analyses: A quantitative tool. International Journal of Social Research Methodology 18: 669-84. [CrossRef]

Gibson, Laura E., and Harold Leitenberg. 2000. Child sexual abuse prevention programs: Do they decrease the occurrence of child sexual abuse? Child Abuse \& Neglect 24: 1115-25. [CrossRef]

Gilbert, Ruth, June Thoburn, Alison Kemp, Peter Sidebotham, Lorraine Radford, Danya Glaser, and Harriet L. Macmillan. 2009. Recognising and responding to child maltreatment. Lancet 373: 167-80. [CrossRef]

Grober, Jacqueline S., and G. Anne Bogat. 1994. Social problem solving in unsafe situations: Implications for sexual abuse education programs. American Journal for Community Psychology 22: 399-414. [CrossRef] 
Gubbels, Jeanne, Claudia E. van der Put, and Mark Assink. 2021a. Schoolprogramma's voor de preventie van kindermishandeling: Resultaten van meta-analytisch, exploratief, en kwalitatief onderzoek [School Programs for the Prevention of Child Abuse: Results of Meta-Analytical, Exploratory, and Qualitative Research]. Amsterdam: University of Amsterdam, Available online: https://pure.uva.nl/ws/files/63 944724/Rapport_voorlichting_scholen.pdf (accessed on 12 October 2021).

Gubbels, Jeanne, Claudia E. van der Put, Geert-Jan J. M. Stams, and Mark Assink. 2021b. Effective Components of School-Based Prevention Programs for Child Abuse: A Meta-Analytic Review. Clinical Child and Family Psychology Review 24: 553-78. [CrossRef]

Gubbels, Jeanne, Mark Assink, Peter Prinzie, and Claudia E. van der Put. 2021c. Why Healthcare and Education Professionals Underreport Suspicions of Child Abuse: A Qualitative Study. Social Sciences 10: 98. [CrossRef]

Guest, Greg, Arwen Bunce, and Laura Johnson. 2006. How many interviews are enough? An experiment with data saturation and variability. Field Methods 18: 59-82. [CrossRef]

Higgins, Deborah S. 2008. An Evaluation of the Challenge Day Program. Master's thesis, Western Michigan University, Kalamazoo, MI, USA.

Highet, G. 2003. Cannabis and smoking research: Interviewing young people in self-selected friendship pairs. Health Education Research 18: 108-18. [CrossRef]

Houssart, Jenny, and Hilary Evens. 2011. Conducting task-based interviews with pairs of children: Consensus, conflict, knowledge construction and turn taking. International Journal of Research E Method in Education 34: 63-79. [CrossRef]

Jonas, S., Paul E. Bebbington, Sally McManus, Howard Meltzer, Rachel Jenkins, Elizabeth Kuipers, Claudia Cooper, Michael B. King, and Terry Brugha. 2011. Sexual abuse against children and psychiatric disorder in England: Results from the 2007 Adult Psychiatric Morbidity Survey. Psychological Medicine 41: 709-19. [CrossRef]

Kenny, Maureen C., Vjolca Capri, Reena R. Thakkar-Kolar, Erika E. Ryan, and Melissa K. Runyon. 2008. Child sexual abuse: From prevention to self-protection. Child Abuse Review 17: 36-54. [CrossRef]

Ko, Susan F., and Merith A. Cosden. 2001. Do elementary school-based child abuse prevention programs work? A high school follow-up. Psychology in the Schools 38: 57-66. [CrossRef]

MacIntyre, Deirdre, and Alan Carr. 2000. Prevention of child sexual abuse: Implications of programme evaluation research. Child Abuse Review 9: 183-99. [CrossRef]

Marivate, Patricia, and Sylvester Ntomchukwu Madu. 2007. Levels of social support and coping strategies in adult survivors of child sexual abuse. Journal of Psychology in Africa 17: 133-36. [CrossRef]

Messman-Moore, Terri L., and Aubrey A. Coates. 2007. The impact of childhood psychological abuse on adult interpersonal conflict: The role of early maladaptive schemas and patterns of interpersonal behavior. Journal of Emotional Abuse 7: 75-92. [CrossRef]

Ministry of Education, Culture, and Science. 2015. Zorgplicht sociale veiligheid leerlingen op school [Duty of Care for Social Safety of Pupils at School]. The Hague: Ministry of Education, Culture, and Science, Available online: https://www.rijksoverheid.nl/onderwerpen/ veilig-leren-en-werken-in-het-onderwijs/documenten/brochures/2016/07/18/zorgplicht-sociale-veiligheid-leerlingen-opschool (accessed on 29 September 2021).

Nickerson, Amanda B., Jenine Tulledge, Margaret Manges, Samantha Kesselring, Timothy Parks, Jennifer A. Livingston, and Melissa Dudley. 2019. Randomized controlled trial of the Child Protection Unit: Grade and gender as moderators of CSA prevention concepts in elementary students. Child Abuse E Neglect 96: 104101. [CrossRef]

NJR. 2013. Jongeren over Kindermishandeling: Onderzoeksverslag NJR Panel [Young People about Child Abuse: NJR Panel Research Report]. Utrecht: NJR, Available online: https:/ / static1.squarespace.com/static/533d1930e4b09659516b85de/t/542d1853e4b08f9cfbc466 c1/1412241491464/jongeren+over+kindermishandeling+lowres_def.pdf (accessed on 22 December 2020).

Pieper, Ivet, and Nickey De Haan. 2017. Adviezen van jongeren en ouders voor het voorkómen van kindermishandeling [Advice from Young People and Parents for the Prevention of Child Abuse]. Amsterdam: Stichting Alexander, Available online: https:/ / st-alexander.nl/wp-content/uploads/2020/10/314_Adviezen-van-jongeren-ouders-voor-het-voorkomen-vankindermishandling_UvA_20160022.pdf (accessed on 23 December 2020).

Rispens, Jan, André Aleman, and Paul P. Goudena. 1997. Prevention of child sexual abuse victimization: A meta-analysis of school programs. Child Abuse E Neglect 21: 975-87. [CrossRef]

Sanderson, Jennifer. 2004. Child-Focused Sexual Abuse Prevention Programs. How Effective Are They in Preventing Child Abuse? Queensland: Crime and Misconduct Commission. Available online: https://www.ccc.qld.gov.au/sites/default/files/Docs/Publications/ CMC/Bulletins\%2Cseries-and-discussion-papers/Research-and-issues-paper-series/Research-and-Issues-Child-focusedsexual-abuse-prevention-programs-2004.pdf (accessed on 4 February 2021).

Scholes, Laura, Christian Jones, Colleen Stieler-Hunt, and Ben Rolfe. 2014. Serious games for learning: Games-based child sexual abuse prevention in schools. International Journal of Inclusive Education 18: 934-56. [CrossRef]

Schönbucher, Verena, Thomas Maier, Meichun Mohler-Kuo, Ulrich Schnyder, and Markus A. Landolt. 2012. Disclosure of Child Sexual Abuse by Adolescents: A Qualitative In-Depth Study. Journal of Interpersonal Violence 27: 3486-513. [CrossRef]

Schönbucher, Verena, Thomas Maier, Meichun Mohler-Kuo, Ulrich Schnyder, and Markus A. Landolt. 2014. Adolescent Perspectives on Social Support Received in the Aftermath of Sexual Abuse: A Qualitative Study. Archives of Sexual Behavior 43: 571-86. [CrossRef]

Stoltenborgh, Marije, Marian Bakermans-Kranenburg, Lenneke R. A. Alink, and Marinus H. van IJzendoorn. 2015. The prevalence of child maltreatment across the globe: Review of a series of meta-analyses. Child Abuse Review 24: 37-50. [CrossRef]

Tong, Allison, Peter Sainsbury, and Jonathan Craig. 2007. Consolidated criteria for reporting qualitative research (COREQ): A 32-item checklist for interviews and focus groups. International Journal for Quality in Health Care 19: 349-57. [CrossRef] 
Topping, Keith J., and Ian G. Barron. 2009. School-based child sexual abuse prevention programs: A review of effectiveness. Review of Educational Research 79: 431-63. [CrossRef]

Walsh, Kerryann, Karen Zwi, Susan Woolfenden, and Aron Shlonsky. 2018. School-based education programs for the prevention of child sexual abuse: A Cochrane systematic review and meta-analysis. Research on Social Work Practice 28: 33-55. [CrossRef]

World Health Organization. 2014. Global Status Report on Violence Prevention 2014. Geneva: World Health Organization, Available online: https:/ / www.who.int/publications/i/item/9789241564793 (accessed on 2 September 2021).

World Health Organization. 2018. European Status Report on Preventing Child Maltreatment. Geneva: World Health Organization, Available online: https://www.euro.who.int/_data/assets/pdf_file/0017/381140/wh12-ecm-rep-eng.pdf (accessed on 10 February 2020).

Yancey, C. Thresa, and David J. Hansen. 2010. Relationship of personal, familial, and abuse-specific factors with outcome following child sexual abuse. Aggression \& Violent Behavior 15: 410-21. [CrossRef] 